\title{
Saúde além da medicina: a invisibilidade do enfermeiro como fonte de informações
} para a imprensa

Health beyond medicine: the invisibility of the nurse as a source of information for the press

Salud más allá de la medicina: la invisibilidad del enfermero como fuente de informaciones para la prensa

\section{Mônica Farias dos Santos}

- Mestranda do Programa de Pós-Graduação em Ciências da Comunicação da Escola de Comunicações e Artes da Universidade de São Paulo (ECA-USP)

- Especialista em Gestão Estratégica em Comunicação Organizacional e Relações Públicas (Gestcorp) pela ECA-USP

- Graduada em Jornalismo pela Faculdade de Comunicação Social Cásper Líbero (Facásper)

- Coautora do livro Gestão de enfermagem: ferramenta para a prática segura

- E-mail: monicasantos68@hotmail.com 


\section{Resumo}

O artigo apresenta os resultados de um estudo exploratório cuja proposta é elucidar as questões que tornam o enfermeiro e seu órgão representativo, o Conselho Regional de Enfermagem de São Paulo (Coren-SP), invisíveis como fontes para jornalistas especializados em saúde nos veículos da capital paulista. A revisão de autores dedicados à comunicação pública, às relações públicas e às teorias de comunicação de massa, além da realização de entrevistas com jornalistas de editorias de saúde de veículos de São Paulo, mostraram possíveis fatores que influenciam a imprensa a não considerar pautar temas de interesse público sugeridos pelo Coren-SP.

PALAVRAS-CHAVE: COMUNICAÇÃO PÚBLICA •INTERESSE PÚBLICO • RELACIONAMENTO COM A IMPRENSA

\section{Abstract}

The article presents the results of an exploratory study that aimed to elucidate the reasons why nurses and their representative body, the Coren-SP, are "invisible" as sources of information for journalists covering health issues in São Paulo city's media. Reviewing authors devoted to public communication, public relations and mass communication theories, in addition to interviews with journalists covering health news in São Paulo city's media, has shown us possible factors influencing the press not to consider stories of guided public interest suggested by Coren-SP.

\section{KEYWORDS: PUBLIC COMMUNICATION・PUBLIC INTEREST・PRESS RELATIONS}

\section{Resumen}

El artículo presenta los resultados de un estudio exploratorio que tiene como objetivo dilucidar las cuestiones que hacen del enfermero y su órgano de representatividad, Consejo Regional de Enfermería de São Paulo (Coren-SP), invisibles como fuentes para periodistas especializados en salud en la prensa de la ciudad de São Paulo. La revisión de los autores dedicados a la comunicación pública, a las relaciones públicas y a las teorías de la comunicación de masa, además de entrevistas con periodistas de editoriales de los vehículos de comunicación de São Paulo, muestran posibles factores que influencian a la prensa a no considerar pautar temas de interés público sugeridos por el Coren-SP.

PALABRAS CLAVE: COMUNICACIÓN PÚBLICA • INTERÉS PÚBLICO • RELACIONES CON LA PRENSA 
D iversas são as profissões da área da saúde responsáveis por desempenhar atividades de assistência ao paciente, sendo que a medicina é a de maior destaque, convertendo-se mesmo em porta-voz de todo e qualquer tema de saúde que venha a ser debatido pela sociedade e pelos meios de comunicação. No entanto, longe dos holofotes, trabalha a enfermagem, maior das categorias de profissionais de saúde do Brasil (quase 1,6 milhão de profissionais, segundo dados de dezembro de 2011, do Conselho Federal de Enfermagem - Cofen), e do mundo (13 milhões, conforme registrado pelo Conselho Internacional de Enfermeiros CIE em julho de 2010).

Dentre os profissionais de sua categoria, o enfermeiro, com base em pesquisa científica e na atuação baseada em evidências bem como por sua postura crítica, é o que dispõe de mais elementos para contribuir com o desenvolvimento da enfermagem como ciência. Um dos aspectos de destaque na atuação do enfermeiro é a sua capacidade para a detecção precoce e prevenção de situações de riscos que, a todo momento, estão presentes nos diversos processos envolvidos na assistência ao paciente. Os erros acontecem, com menor ou maior repercussão, todos os dias, nas instituições de saúde de todo o país. As situações que oferecem riscos à integridade física do paciente são as mais variadas, grande parte delas apenas esperando para acontecer.

Isso considerado, o Conselho Regional de Enfermagem de São Paulo (Coren-SP), autarquia que congrega os profissionais da categoria no estado de São Paulo, lançou em 2010 a campanha "Enfermagem pela segurança do paciente". Além das ações da campanha, o órgão voltou-se também para a ampla divulgação do assunto para a sociedade por meio da imprensa. Os veículos foram pautados quanto aos riscos presentes na assistência, com o objetivo de conscientizar todos os potenciais usuários do sistema de saúde sobre a necessidade de se munirem de conhecimento e atuarem como agentes de sua própria segurança ou a de um familiar. No entanto, ao longo de toda a campanha, nenhum veículo da capital paulista interessou-se pelas pautas.

A observação do comportamento dos jornalistas da imprensa do município de São Paulo, ao receberem as sugestões de pauta oriundas da assessoria de imprensa do Coren-SP, tem sido um termômetro para avaliação de seu interesse pela cobertura dos temas. Sua reação é, em geral, evasiva ou indiferente. Talvez isso se deva ao fato de eles ignorarem quem é e o que faz o enfermeiro, preferindo confiar, quase que exclusivamente, em fontes médicas para desenvolver suas pautas sobre saúde. Essa dúvida despertou em nós o interesse em investigar as razões que os levam a não considerarem pautar os temas sugeridos pelo Coren-SP, em trabalho por nós desenvolvido anterormente. (Santos, 2011). 


\section{AS AÇÕES DE COMUNICAÇÃO DOS ÓRGÃOS PÚBLICOS}

A Lei Federal 7.498, de 25 de junho de 1986, regulamenta o exercício profissional de enfermagem e define, em seu artigo 11, que ao enfermeiro cabe, dentre várias atribuições: planejamento dos serviços da assistência de enfermagem; assistência de enfermagem à gestante, parturiente e puérpera; acompanhamento da evolução e do trabalho de parto; execução do parto sem fatores de risco; educação em saúde para a população.

No Brasil, a fiscalização e o controle do exercício de profissões regulamentadas por lei foi assumida por autarquias federais. Segundo esse entendimento, foram criados, pela Lei 5.905, de 12 de julho de 1973, o Conselho Federal de Enfermagem (Cofen) e suas seções regionais, responsáveis por assegurar à sociedade que apenas profissionais habilitados exerçam a profissão. É uma obrigação imposta por lei federal e que demanda seu cumprimento, seja pela fiscalização por essas entidades, seja por outros mecanismos não explicitados. Um desses mecanismos é a comunicação, de cunho informativo e educativo, com toda a sociedade.

Compreendendo-se que os conselhos de fiscalização do exercício profissional são autarquias federais, eles devem pautar suas ações de comunicação pelo caráter educativo e informativo que cabe a um órgão público. Pierre Zémor (apud Novelli, 2009, p. 494) ensina que as mensagens dos entes públicos

servem ao interesse público - o conteúdo das informações tem caráter global e pertinente a toda a sociedade ou a parte dela. Interesses privados não podem prevalecer sobre os interesses de todos nem figurar como componente da comunicação pública.

O alerta faz-se pertinente, pois a comunicação de órgãos públicos não pode adquirir os contornos das ações de comunicação do setor privado. Mas é certo que, embora os fins da comunicação pública e da comunicação de entes privados sejam diversos, os meios para alcançar seus propósitos bebem da mesma fonte: os princípios da comunicação organizacional. Sobre a adoção desse caminho, Paulo Régis Salgado (2011, p. 247) sugere que

qualquer projeto ou programa dos governos deve (...) basear-se num sólido programa de comunicação e relações públicas, com o objetivo de comunicar, esclarecer, educar e conscientizar os cidadãos/contribuintes, tornando-os, também, partícipes da obra governamental.

Assim, apoiar-se sobre os princípios e as práticas das relações públicas e da comunicação organizacional parece ser a opção natural para o Coren-SP desenvolver suas ações comunicativas na busca de seus propósitos. $E$, considerando que os métodos e as técnicas das ações de comunicação nascidas nos órgãos públicos bebem da fonte da comunicação organizacional e das relações públicas, as atividades de assessoria de imprensa reproduzem as práticas desse campo teórico. Emprestando de Haswani (2003) a citação que ela faz de Manuel Carlos Chaparro, 
assessoria de imprensa é a prática do jornalismo ao nível da fonte, para assegurar aos meios de comunicação informação de boa qualidade, sob o ponto de vista da técnica jornalística e da relevância social. A assessoria de imprensa, tal como a entendemos, deve existir somente em instituições que, por dever e/ou competência, geram atos e fatos de interesse público (Chaparro, apud Haswani, 2003, p. 37).

A atividade de assessoria de imprensa, desempenhada conforme a definição proposta por Chaparro - em especial no que concerne aos "fatos de interesse público" -, é fundamental para que os entes públicos deem ciência aos jornalistas - e, por intermédio destes, à sociedade - dos assuntos que são de interesse de todo cidadão. Informações importantes originadas nos órgãos públicos, sobre temas como transportes, saúde, educação, entre outros, nem sempre merecem a atenção espontânea dos jornalistas. Isso ocorre especialmente em relação a assuntos que fogem ao usual da cobertura dos veículos ou que sejam estranhos ao repertório básico do próprio jornalista quanto ao que ele acredita ser relevante, de interesse público, ou mesmo ao que/quem ele considera e entende como fonte.

\section{O CASO DA CAMPANHA PELA SEGURANÇA DOS PACIENTES}

Em 2002, a Organização Mundial de Saúde (OMS) lançou uma campanha de conscientização para todos os seus países-membros, alertando-os sobre a necessidade de estarem atentos a uma questão que, a cada ano, tem chamado mais e mais a atenção das autoridades de saúde ao redor do mundo: aproximadamente cinco milhões de pacientes por ano perdem suas vidas como consequência de erros humanos, de falhas no processo de assistência à saúde. Por tratar-se de tema de vital importância, essa questão foi amplamente abordada pelo Coren-SP ao longo de 2010.

Uma das frentes de atuação do Coren-SP tinha por objetivo o esclarecimento de toda a sociedade paulista quanto à urgência e relevância do tema - em total acordo com o que também é proposto pela OMS, em seu programa "Pacientes pela segurança do paciente: participação do paciente". A compreensão do Coren-SP foi a de que, embora a garantia da segurança na assistência à saúde seja uma obrigação dos prestadores de serviços, ao considerarmos o fator "erro humano", é impossível descartá-lo por completo. Dessa forma, segundo o entendimento do órgão, usuários do sistema de saúde também poderiam atuar em favor de sua própria segurança. Munidos de conhecimento e das informações transmitidas pelo Coren-SP, estariam em melhores condições de atuar como uma "barreira" adicional ao fator "erro do profissional". Como bem define Novelli (2009, p. 487), a respeito das informações emitidas pelos órgãos públicos,

o interesse público, objetivo de todo processo de comunicação, é o pressuposto da atuação das relações públicas governamentais. É com foco no bem-estar da coletividade que são defi- 
nidas as ações públicas, cabendo à área de relações públicas, por meio de programas de comunicação, traçar estratégias para que a população se engaje nas ações públicas e participe da tomada de decisões.

Embora o Coren-SP seja um órgão público com 36 anos de atuação, existia a consciência, por parte de seus dirigentes de então, de que um percentual muito pequeno da sociedade o conhece ou sabe qual o propósito de sua atuação. Assim, baseado nessa percepção, ele entendeu a necessidade de contar com a intermediação de um ente que, presente no cotidiano de todo cidadão, já construiu sua imagem de credibilidade perante esse público. Nesse contexto, a imprensa paulista foi compreendida como stakeholder estratégico na construção de uma cultura de oferta de assistência à saúde mais segura à sociedade.

Durante os meses de março, abril e maio de 2010, a assessoria de imprensa do Coren-SP realizou um esforço de divulgação dos diversos aspectos da assistência à saúde que poderiam representar riscos para a segurança dos pacientes. Chamou-se a atenção para o fato de que os riscos no processo de assistência estão em todo e qualquer lugar. Seja num grande hospital geral público de referência, seja numa instituição privada de primeira linha. Em maior ou menor grau, os riscos - evitáveis - à vida do paciente se fazem presentes em todos eles.

Os releases enviados às editorias de saúde tratavam de temas como a necessidade de mudanças nos processos de preparação de cirurgias, para evitar ocorrências como, entre tantas outras: procedimentos em membros errados ou até com o paciente errado; erros como a transfusão de sangue de tipo diferente daquele do paciente; ou erros na administração de medicamentos. Sobre tudo isso já se leu ou já se ouviu falar por meio da imprensa. O Coren-SP acreditava que, se divulgados com ênfase pela imprensa, tais fatos despertariam a atenção da população, tanto para que pudessem atuar como agentes de sua própria segurança, como também para que pudessem se organizar e cobrar investimentos das instituições que garantissem índices reduzidos de falhas em processos passíveis de causar algum dano aos pacientes.

Como resultado do esforço de divulgação do tema em todos os principais veículos da imprensa do estado de São Paulo, apenas se conseguiu a menção de um evento: o $1^{\circ}$ Fórum de Enfermagem - Segurança doPaciente -, na agenda semanal de dois veículos impressos (Diário de São Paulo e Folha de S.Paulo).

Depois de enviar os releases a jornalistas especializados, mesmo realizando um follow up para tentar sensibilizá-los quanto à urgência do tema; mesmo contando com nomes nacionais e internacionais "de peso" como sugestões de fonte para entrevistas, nada disso parece ter chamado a atenção dos colegas nas redações. Uma abordagem ampla teria representado um auxílio adicional ao esforço mundial para poupar cinco milhões de vidas, todos os anos. Se os fatos e números apresentados não foram suficientes para que as redações pautassem o tema em seus veículos, o que teria faltado à estratégia de divulgação? 


\section{CONCEITO DO VALOR-NOTÍCIA E A PRESSUPOSTA (I)LEGITIMIDADE DA FONTE}

Definidos por Valter A. Rodrigues (2003, p. 209) como "superfícies privilegiadas de visibilidade dos acontecimentos", os meios de comunicação, em decorrência de seu alcance global, seriam, de acordo com sua avaliação, a principal, ou talvez mesmo a "única tribuna no qual o embate entre Estado e sociedade civil poderia se realizar".

A proposta de espaço para o embate democrático de ideias, de livre expressão de pensamento, de convivência de opostos que esse conceito de "tribuna" sugerido por Rodrigues pode suscitar, sucumbe à realidade do que são de fato e como se articulam as informações recebidas e retransmitidas pelos meios de comunicação, em especial as produções de conteúdo jornalístico.

Mauro Wolf (2003, p. 196) abraça a visão bastante lúcida e corajosa de David Altheide, para quem "as notícias são o que os jornalistas definem como tais". Sem qualquer julgamento baseado em valores, Wolf dedica todo o terceiro capítulo de sua obra Teorias das comunicações de massa a apresentar os mecanismos que levam à construção das notícias e os critérios conscientes adotados por jornalistas no momento de definirem suas pautas diárias, em meio a um sem-número de notícias possíveis.

Às tentativas de atrair a atenção da mídia ou enquadrar-se em sua lógica se impõe mais um revés: o de que nem todos os fatos conhecidos pela imprensa se tornam notícias levadas ao público. Os veículos costumam guiar-se por critérios de noticiabilidade. Mauro Wolf (2003, p. 195-196) explica que

a noticiabilidade é constituída por complexos requisitos que se exigem para os eventos (...), para adquirirem a existência pública de notícia. Tudo o que não responde a esses requisitos é "selecionado", uma vez que não se mostra adequado às rotinas de produção e aos cânones da cultura profissional: não conquistando o estatuto público de notícia, permanece simplesmente um evento que se perde na "matéria-prima" que o aparato informativo não consegue transformar e que, portanto, não deverá fazer parte dos conhecimentos do mundo, adquiridos pelo público por meio da comunicação de massa.

Tendo isso definido, Wolf (2003, p. 202) conclui que o valor da notícia é um componente do critério de noticiabilidade, utilizado, segundo alguns parâmetros, para definir "os elementos dignos de ser incluídos no produto final". Ao investigarmos os aspectos descritos pelo autor em relação ao conceito do valor-notícia, encontramos referências ao tema em texto de Luiz Alberto Farias (2011, p. 114), o qual explica que

a importância e o interesse de determinado assunto terão relação com o grau e o nível hierárquico dos indivíduos envolvidos no acontecimento noticiável, além do impacto sobre a opinião pública e da quantidade de pessoas que o acontecimento envolva. 
Portanto, conforme o princípio do valor-notícia e o índice de noticiabilidade do assunto em questão - o tema segurança do paciente -,este atende a, pelo menos, dois quesitos destacados pelo autor: impacto sobre a opinião pública (trata-se de tema ligado à garantia de preservação da vida); e quantidade de pessoas envolvidas (milhões, em todo o mundo). Esses dois fatos, por si sós, já demandariam a atenção dos meios. Porém, como tal não ocorreu, era necessário, ainda segundo os pressupostos do conceito de valor-notícia, aprofundar a análise.

Wolf (2003, p. 208) elenca, como o primeiro dentre os critérios de noticiabilidade de um fato, a questão do "grau e nível hierárquico dos indivíduos envolvidos no acontecimento noticiável". Na situação abordada no presente estudo, essa classificação não é pertinente, pois envolvidos são todos os usuários do sistema de saúde. Por isso, optamos por realizar uma leitura alternativa para esse critério, não encontrada em Wolf ou em outro autor que tenha abordado o tema. Ampliamo-lo para a análise do emissor da informação, de seu grau e nível hierárquico. Poderia o fato de a campanha para a promoção da segurança do paciente ser realizado por um órgão público voltado para a fiscalização do exercício da enfermagem ter, de alguma forma, influenciado os jornalistas, quando da aplicação dos critérios de noticiabilidade? Outra vertente de análise sugerida, ainda conforme uma proposta de adaptação dos critérios sugeridos por Wolf, pode ser compreendermos quem deve ser, para a imprensa, o emissor das informações sobre temas da saúde: poderia ser o enfermeiro, representado pelo Coren-SP, considerado um emissor inesperado de informações de tamanho peso e significado?

\section{O ENFERMEIRO, ESSE GRANDE DESCONHECIDO}

Jeanne Marie R Stacciarini et al. (1999) realizaram um estudo que buscava detectar, entre os visitantes do campus da Universidade Federal de Goiás (UFGO), qual seria a sua opinião sobre quem é o enfermeiro. A representação mais frequente mencionada espontaneamente pelos pesquisados foi a de "auxiliar do médico". Uma das conclusões das autoras, diante dessa prevalência, foi a de que "essa representação denota que o enfermeiro é submisso ao médico; alguém que atua mediante as ordens do médico".

Em outra pesquisa, conduzida por Ligia Fahl Kemmer e Maria Júlia Paes da Silva (2007), foi proposto pelas autoras compreender a visão e opinião que profissionais comunicadores guardam do enfermeiro. Desejavam desvendar as razões pelas quais a enfermagem, apesar de possuir "um corpo próprio de conhecimento científicos, buscando, por meio de estudos e pesquisas, a sua definição como ciência", não conta com o reconhecimento social de suas ações. Como primeira conclusão, o estudo mostrou que "as representações sociais identificadas em diversos segmentos da sociedade e aquelas veiculadas notadamente pela mídia, refletem (...) um profissional sem poder, sem autonomia, sem conhecimento, sem voz".

Em relação à percepção da representação do enfermeiro pelos profissionais de comunicação entrevistados, as mesmas autoras identificaram "a figura do enfermeiro como 'a sombra do mé- 
dico' e, muitas vezes, de forma estereotipada". Segundo suas observações, os entrevistados reproduziram uma opinião já constatada em outros estudos a respeito da imagem do enfermeiro, nos quais este "é caracterizado por realizar tarefas simplesmente técnicas, subordinado à área médica, identificado como auxiliar de médico e atuando em profissão denotativa de mão de obra barata". A falta de visibilidade do enfermeiro e de seu potencial diante da a imprensa foi ilustrada pelas autoras num depoimento de um de seus entrevistados (apud Kemmer; Silva, 2007).

Fui fazer uma matéria e então descobri que a principal autoridade em amamentação aqui na cidade era uma enfermeira, não era um médico. Foi muito engraçado porque nesta ocasião eu trabalhava no jornal e a matéria era específica sobre amamentação e obviamente que eu fui primeiro a pediatras, ginecologistas.

\section{ENTREVISTAS: DESCOBRINDO O QUE PENSA A IMPRENSA DA CAPITAL PAULISTA}

Os questionamentos do trabalho em relação à percepção da imprensa acerca da enfermagem como um possível fator concorrente para a falta de aproveitamento das pautas sobre segurança do paciente enviadas pelo Coren-SP aos jornalistas motivou a realização de entrevistas com repórteres de alguns veículos da capital paulista. Foram enviados questionários contendo perguntas abertas e fechadas para jornalistas de doze grandes veículos, entre rádios, emissoras de televisão, jornais e portais de internet. O critério adotado para seleção dos veículos foi a existência de contatos prévios de seus jornalistas com o Coren-SP. Dos doze questionários enviados, apenas cinco retornaram. A análise foi realizada sobre esse total de questionários respondidos.

Uma única pergunta, fechada, porém, abordando diferentes aspectos da mesma questão, iniciou o questionário. Perguntados sobre qual, dentre os profissionais de saúde elencados em cada item, priorizariam como fontes para entrevistas sobre temas diversos da saúde, os jornalistas deveriam numerar, por ordem de prioridade, do profissional que considerassem mais relevante ao menos relevante para sua pauta. A seguir, comentaremos o que pode ser constatado a respeito de três dos sete temas para os quais sugerimos a indicação das possíveis fontes para os jornalistas entrevistados.

O primeiro tema proposto foi o parto normal. Dos cinco respondentes, dois optariam por um médico como primeira fonte. Nenhum deles escolheu o enfermeiro como primeira opção. Para três entrevistados, o enfermeiro seria a sua opção menos provável para tornar-se fonte de suas matérias. É interessante notar que, dentre os quatro profissionais elencados como opções (médico, enfermeiro, obstetriz, parteira), apenas o médico e o enfermeiro podem, legalmente, realizar o parto normal.

A segunda pauta sugerida foi sobre o aleitamento materno. Quatro dos entrevistados indicaram o nutricionista como sua fonte primária de informações. Um entrevistado considerou o médico como sua primeira opção. Três dos entrevistados indicaram o enfermeiro como sua última opção. 
Cabe registrar que uma pauta sobre aleitamento materno que utilizasse um nutricionista como fonte contaria apenas com informações a respeito dos aspectos nutricionais do leite. Quanto ao foco principal da pauta - dificuldades para amamentar, técnicas que a mãe deve conhecer para sentir-se confortável e oferecer conforto à criança, entre outros aspectos -, esses tópicos seriam plenamente esclarecidos se os jornalistas optassem pelo enfermeiro como fonte.

A respeito da sugestão de pauta sobre exame pré-natal, três entrevistados escolheriam um médico como fonte. Outros dois escolheriam uma obstetriz como sua primeira opção. O enfermeiro figura como segunda opção para dois entrevistados e como última opção para outros dois. Para um dos entrevistados, o enfermeiro nem mesmo seria considerado como fonte. Assim como na autorização para realização de parto normal, também a realização dos exames pré-natal é atividade legalmente restrita apenas a médicos e enfermeiros.

Embora essas perguntas de múltipla escolha com opção de ranqueamento já tenham servido ao propósito de esclarecer o grau de conhecimento dos jornalistas a respeito das competências e do conhecimento técnico e científico do enfermeiro, foi na última pergunta, aberta, que sua opinião sobre esse profissional se apresentou de forma clara. Ficou evidente, por meio das palavras utilizadas nas respostas, a reprodução da percepção que se tem do enfermeiro na sociedade:

Para mim o enfermeiro sempre foi o auxiliar do médico (Entrevistado 2).

É o profissional que presta serviços auxiliares aos de um médico em um hospital (Entrevistado 1).

Um auxiliar na cirurgia, no atendimento (Entrevistado 5).

O enfermeiro também foi equivocadamente identificado pelos jornalistas como o responsável pelas ações que, na verdade, são cotidianas dos auxiliares e técnicos de enfermagem, como demonstram as respostas à entrevista:

Serve para aplicar uma injeção, segurar paciente quando preciso, passar instrumentos para o cirurgião, fazer os primeiros socorros (Entrevistado 2).

(...) auxílio ao tratamento em geral prescrito pelo médico, como dar orientações, ministrar remédios, entre outros [itens] (Entrevistado 4).

Ao recordarmos os passos seguidos para tentar desvendar as razões que provocaram a resistência dos jornalistas da capital paulista em aceitar pautar os temas propostos pelo Coren-SP, a teoria mostrou ser possível que uma associação de todos os fatores mencionados contribua para essa "invisibilidade" do enfermeiro e de seu órgão representante. No entanto, uma questão mais profunda parece se desenhar, ao percebermos, por meio das entrevistas, o quanto a imagem do enfermeiro na sociedade pode contribuir para a difícil construção de credibilidade e de consistência técnica e científica do órgão público que representa a categoria. 


\section{CONSIDERAÇÕES FINAIS}

Em dezembro de 2010, o país todo acompanhou, por meio da imprensa, as notícias a respeito da morte de Stephanie dos Santos Teixeira. Internada no Hospital São Luiz Gonzaga, na capital paulista, a menina, de doze anos, foi admitida no pronto-socorro da instituição apenas para tratar-se de uma leve indisposição gastrointestinal. Saiu de lá morta. A auxiliar de enfermagem responsável na ocasião por preparar o soro a ser administrado na criança cometeu um erro: pegou o recipiente com vaselina líquida, em vez daquele que continha o soro fisiológico. Vaselina na veia provoca a morte em instantes.

"Justiça!", era o que se ouvia dos meios de comunicação a respeito da morte evitável de uma criança. Morte evitável. Exatamente o tema sobre o qual o Coren-SP trabalhou ao longo daquele ano junto àqueles mesmos jornalistas que buscavam informações a respeito da punição a ser aplicada à auxiliar de enfermagem.

O Brasil, país-membro da Organização Mundial de Saúde, firmou, em 2002, o compromisso de unir-se aos esforços de poupar as vidas perdidas anualmente, decorrentes de erros no processo de assistência à saúde. O Coren-SP, cumprindo com sua obrigação de tornar público um tema que alertaria a sociedade, os serviços de saúde e os governos para uma urgente necessidade de mobilização, acreditou e confiou na força e no poder da imprensa para atuar como parceira em sua missão. Mas, ao que parece, o alerta de que era necessário salvar cinco milhões de vidas apresentou um valor-notícia baixo. E, assim, a menina Stephanie Teixeira engrossou a trágica estatística.

O percurso metodológico adotado no trabalho aqui comentado levou a descobertas que apontaram para algumas constatações: enfermeiros não são considerados fontes de informação para os jornalistas, pois estes entendem o enfermeiro como ajudante de médicos. Por extensão, as pautas apresentadas à imprensa pelo órgão representativo dos enfermeiros carecem de atrativos (baixo valor-notícia) e de legitimidade - pois, para o jornalista, saúde é área de domínio da medicina e não da enfermagem, que é apenas auxiliar do médico, como foi possível constatar por meio das entrevistas.

Embora o estudo tenha servido ao propósito de lançar alguma luz sobre as razões pelas quais a imprensa paulistana ignorou as pautas sobre segurança dos pacientes propostas pelo Coren-SP, apenas essa compreensão não será suficiente para fazer chegar à sociedade as informações e os alertas que os enfermeiros, por meio de seu órgão de classe, têm a apresentar. Mudar a forma de atuação dos meios de comunicação é proposta inviável.

Resta ao órgão aprender - e compreender - os caminhos trilhados pela lógica da comunicação de massa e desenvolver novas propostas de atuação para alcançar e sensibilizar os jornalistas. Mesmo em tempos de comunicação em rede, na qual todo cidadão é "mídia" em potencial, ainda assim - e, possivelmente, por muito tempo ainda - os jornalistas serão stakeholders imprescindíveis e estratégicos para os órgãos públicos. 


\section{REFERÊNCIAS}

FARIAS, Luiz Alberto. Relações com a imprensa. In: FARIAS, Luiz Alberto (Org.). Relações públicas estratégicas. São Caetano do Sul (SP): Difusão: 2011. p. 109-118.

HASWANI, Mariângela Furlan. Quem agenda quem: estudo das relações entre assessorias de imprensa do setor público e veículos jornalísticos na cidade de São Paulo. 2003. Dissertação (Mestrado em Ciencias da Comunicação) - Escola de Comunicações e Artes, Universidade de São Paulo.

KEMMER, Ligia Fahl; SILVA, Maria Júlia Paes da. A visibilidade do enfermeiro segundo a percepção de profissionais de comunicação. Revista Latino-Americana de Enfermagem (on-line), v. 15, n. 2, mar.-abr. 2007.

NOVELLI, Ana Lúcia R. Relações públicas governamentais. In: KUNSCH, Margarida M. Krohling (Org.). Relações públicas: história, teorias e estratégias nas organizações contemporâneas. São Paulo: Saraiva, 2009. p. 485-509.

RODRIGUES, Valter A. Poder e [im]potência da mídia:a alegria dos homens tristes. In: BARROS FILHO, Clóvis de (Org.). Comunicação na pólis: ensaios sobre mídia e política. 2 ed. Petrópolis: Vozes, 2003. p. 209-226.

SALGADO, Paulo Régis. Comunicação organizacional: a ótica das relações públicas governamentais. In: FARIAS, Luiz Alberto (Org.) Relações públicas estratégicas. São Caetano do Sul (SP): Difusão, 2011. p. 247-262.

SANTOS, Mônica F. A (in)visibilidade do enfermeiro como fonte de informações para a imprensa. Monografia (Especialização em Gestão Estratégica de Comunicação Organizacional e Relações Públicas) - Escola de Comunicações e Artes da Universidade de São Paulo, 2011.

STACCIARINI, Jeanne Marie R.; ANDRAUS, Lourdes M. S.; ESPERIDIÃO, Elizabeth; NAKATANI, Adélia K. Quem é o enfermeiro? Revista eletrônica de enfermagem, a. 1, n. 1, out.-dez. 1999. Disponível em: <http://www. revistas.ufg.br/index.php/ fen/index>. Acesso em: 13 abr. 2011.

WOLF, Mauro. Teorias das comunicações de massa. 4. ed. São Paulo: Martins Fontes, 2003.

Recebido em: 05.03.2012 / Aceito em: 04.06.2012 